INVITED PAPER Special Issue on the Past, Present, and Future of Communications Technologies in the IEICE

\title{
R\&D of 3M Technologies towards the Realization of Exabit/s Optical Communications
}

\author{
Toshio MORIOKA ${ }^{\dagger, \dagger+* a)}$, Fellow, Yoshinari AWAJI ${ }^{\dagger \dagger}$, Member, Yuichi MATSUSHIMA ${ }^{\dagger \dagger \dagger}$, \\ and Takeshi KAMIYA ${ }^{\dagger \dagger \dagger}$, Fellows
}

\begin{abstract}
SUMMARY Research efforts initiated by the EXAT Initiative are described to realize Exabit/s optical communications, utilizing the $3 \mathrm{M}$ technologies, i.e. multi-core fiber, multi-mode control and multi-level modulation.

key words: optical communications, space-division multiplexing, multicore fiber, few-mode fiber, mode-division multiplexing
\end{abstract}

\section{Introduction}

Over the last thirty years, the optical communication technologies on which the present communication networks are based have enabled an increase in transmission capacity per fiber by more than four orders of magnitude driven by major technological innovations such as ultrafast time-division multiplexing (TDM) electrical circuits, wavelength-division multiplexing (WDM)/Erbium-doped fiber amplifiers (EDFAs) and digital coherent technology as shown in Fig. 1, realizing the capacity increase from $400 \mathrm{Mbit} / \mathrm{s}$ to $8 \mathrm{Tbit} / \mathrm{s}$ per fiber. If we assume that the data traffic continues to increase by $40-50 \%$ per year, a capacity increase by four to five orders of magnitude is expected for the next thirty years although the present optical communication systems based on singlemode fibers (SMFs) have a fundamental capacity limit of $100 \mathrm{Tbit} / \mathrm{s}$ per fiber. Therefore, it was obvious in mid 2000s that we need to start developing novel optical transmission lines (fibers) and transmission technologies to support well over Pbit/s capacity per fiber and Ebit/s throughput in the core networks to realize Tbit/s access speed per user [1]-[6].

This article reviews innovative research efforts to meet this challenge initiated by a Japanese research initiative, EXAT (EXtremely Advanced Transmission) Initiative, the first of its kind in the world, which started as early as in 2008 and has lead the world research since then, making major technological milestones [2]. Firstly, physical lim-

\footnotetext{
Manuscript received November 7, 2016.

Manuscript revised February 10, 2017.

Manuscript publicized March 22, 2017.

$\dagger$ The author was with NTT Corporation, Yokosuka-shi, 2390847 Japan.

${ }^{\dagger}$ The authors was and is with NICT, Koganei-shi, 184-8795

$\dagger^{\dagger}$ The author is with Waseda University, Tokyo, 162-0041 Japan.

$+t^{\dagger \dagger}$ The author is with The University of Tokyo, Tokyo, 113-8656 Japan.

*Presently, with Technical University of Denmark, $2800 \mathrm{Kgs}$. Lyngby, Denmark.

a)E-mail: tomo@fotonik.dtu.dk

DOI: 10.1587/transcom.2016PFI0018
} Japan.

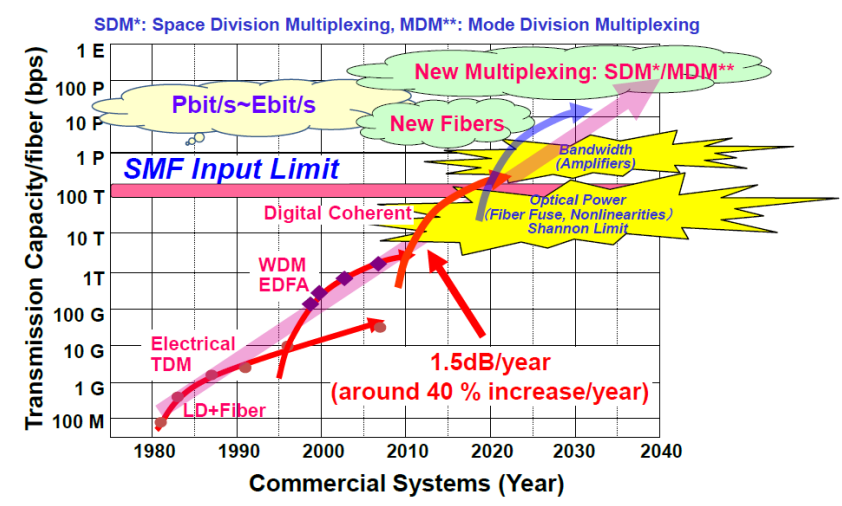

Fig. 1 Evolution of transmission capacity per fiber.

its of the present optical communication systems are briefly identified. Secondly, the EXAT Initiative and the 3M technologies it proposes are described. Thirdly, recent progress in SDM technologies is briefly reviewed focusing on novel multi-core fibers (MCFs) which originated in Japan, and transmission demonstration using them. Lastly, future perspectives towards more capacity and commercialization are described.

\section{Physical Limits of Present Optical Communication Systems}

Transmission capacity per fiber is a good measure of optical network capacity and has been rapidly approaching its limit of $100 \mathrm{Tbit} / \mathrm{s}$ as depicted in Fig. 1 where there are three major physical limiting factors, which are optical nonlinear effects in optical fibers, bandwidths of optical amplifiers, and fiber fuse phenomenon where the fiber core melt-down occurs and propagates towards the optical source, destroying the whole systems.

As shown in Fig. 2, the total transmission capacity is defined by a product of spectral efficiency (SE) and a signal bandwidth. The SE is in fact limited by a theoretical limit called "Shannon limit" curve (shown in the left inset of the figure) which is further limited by the signal distortion caused by various optical nonlinear effects, resulting in a theoretical maximum peak. These nonlinear phenomena include self-phase modulation (SPM), cross-phase modulation (XPM), four-wave mixing (FWM) etc. generated in optical fibers, which cause the maximum transmission capacity of the present single-mode fiber to be around $100 \mathrm{Tbit} / \mathrm{s}$. The 


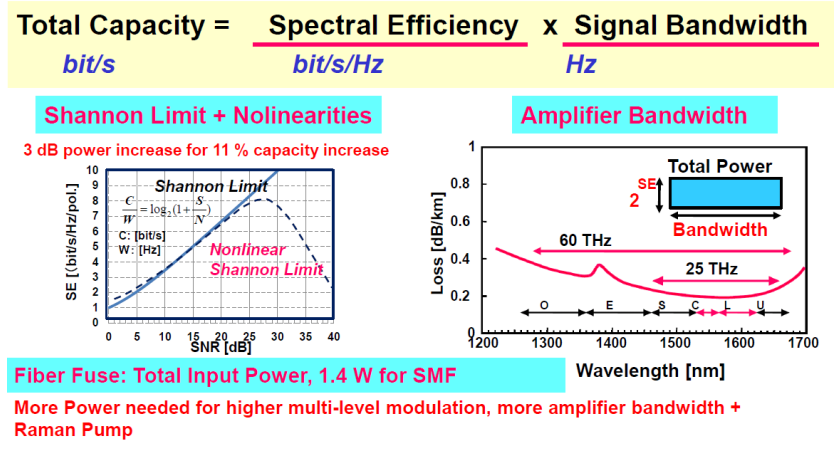

Fig. 2 Total capacity and its limiting factors.

amplifier bandwidths are also limited, to around $40 \mathrm{~nm}$ in the case of rare-earth doped fiber amplifiers and around $100 \mathrm{~nm}$ for Raman amplifiers. Presently, low-loss $1.5 \mu \mathrm{m}$ bands of C-band $(1530 \mathrm{~nm}-1565 \mathrm{~nm})$ or L-band $(1565 \mathrm{~nm}-1625 \mathrm{~nm})$ are being used for long haul transmission systems. The total amplifier bandwidth including S-band (1460 nm-1530 nm) or including all the other bands in the communication bands, i.e., O-band, E-band, S-band, U-band, amounts to around $15 \mathrm{THz}$, or $60 \mathrm{THz}$, respectively, resulting in the maximum potential capacity of around $150 \mathrm{Tbit} / \mathrm{s}$, or $600 \mathrm{Tbit} / \mathrm{s}$, if we assume an SE of $5 \mathrm{bit} / \mathrm{s} / \mathrm{Hz}$ per polarization. However, the optical power limitation from the fiber fuse determines the ultimate capacity. It should be noted that recently developed distributed Raman amplifier systems requiring pumping powers of several hundred $\mathrm{mW}$ up to $\mathrm{W}$ pause a big challenge where their pump powers are approaching the fiber fuse propagation threshold of around $1.2 \sim 1.5 \mathrm{~W}$.

\section{EXAT Initiative and $3 M$ Technologies}

\subsection{EXAT Initiative}

A collaborative study group called "EXAT (EXtremely Advanced Transmission) Initiative" was organized in January 2008 by NICT (the National Institute of Information and Communications Technology, Japan), gathering 25 members from industries, academia, and national institutes in order to develop break-through technologies to substantially increase the transmission capacity to well over Pbit/s per fiber. In the Initiative, we focused on identifying ultimate physical limitations, i.e., the amount of optical power (capacity) that can be transmitted safely in optical fibers, the bandwidth for optical amplification, and the capacity of optical submarine cables systems limited by the electrical power consumed by the optical amplifier repeaters. Most specifically, we proposed the use of the last degree of freedom, "space" for multiplexing and the need to develop new optical fibers (MCFs [7], few-mode fibers (FMFs)) and new multiplexing schemes, namely, space-division multiplexing (SDM) and mode-division multiplexing (MDM) [8] as shown in Fig. 1 .

Figure 3 summarizes how EXAT has developed and evolved for the last nine years since 2008 as well as major research activities around the world [9]-[40]. It should be noted that outside Japan, research has been more focused on FMFs, and most MCFs including FM-MCFs have been designed and fabricated in Japan. After its first period in 2008, it organized EXAT 2008, the first international symposium of its kind in Tokyo in November, 2008, reporting their work on new optical fibers and SDM technologies with clear messages that there is a rapidly approaching limit of the optical communication systems and that we need to develop sustaining new technologies. The second term EXAT Initiative in 2009 discussed specific technological issues to tackle towards the creation of national projects. Each term produced a report and a book entitled "Innovations in Optical Fiber Communications Technologies" were published in 2012 based on the reports [14]. The NICT EXAT Initiative was then inherited by IEICE EXAT study group which was established in 2010 and has continued its vigorous activities, organizing 14 international workshops, symposia, including EXAT 2008, EXAT 2013 and EXAT 2015.

The other important achievement by the EXAT initiative is that it led to the creation of a series of Japanese national projects to further develop the ideas proposed by EXAT. Figure 4 depicts three projects which are i-FREE (Innovative Optical Fiber Technologies: 2010-2012), i-ACTION (Innovative Optical Communication Infrastructure: 2011-2015) and i-FREE ${ }^{2}$ (Innovative Optical Fiber \& Communication Technology for Exa-bit Era with SDM: 2013-2018). In 2016, another new project "R\&D of Space-Division Multiplexing Photonic Node" (2016-2020) started. Furthermore, an EU-Japan coordinated R\&D project on "Scalable And Flexible optical Architecture for Reconfigurable Infrastructure (SAFARI)"(2013-2017) has been created linking the Japanese EXAT community and the European related partners, commissioned by the Ministry of Internal Affairs and Communications (MIC) of Japan and EC Horizon 2020. The Japanese national projects have been leading this most advanced research field on SDM technologies in the world especially MCF technologies, setting several world records such as $1 \mathrm{Pbit} / \mathrm{s}$ transmission (2012) [23], 1 Ebit/s-km transmission (2013) [26], [27], and $2 \mathrm{Pbit} / \mathrm{s}$ (2015) [19], [29].

\subsection{Three-M (3M) Technologies}

In the EXAT initiative of the first term (2008), we explored new fibers making use of "space" dimension, which have potentials of substantially increasing the transmission capacity, and investigated two types of fibers, namely, multi-core fibers (MCFs) and few-mode fibers (FMFs) or multi-mode fibers (MMFs) depending on the number of modes they can carry as shown in Fig. 5. In MCFs, cores can be arranged so that the propagation mode in each core is either coupled with those in other cores (coupled) or not (un-coupled). In FMFs/MMFs, different modes in a core normally couple over some distances and therefore, multiple-input, multipleoutput (MIMO) is usually required.

Based on these new fibers, EXAT Initiative identified three major fundamental technologies, namely, "Mutil-core Fiber", "Multi-mode Control" and "Multi-level Modula- 


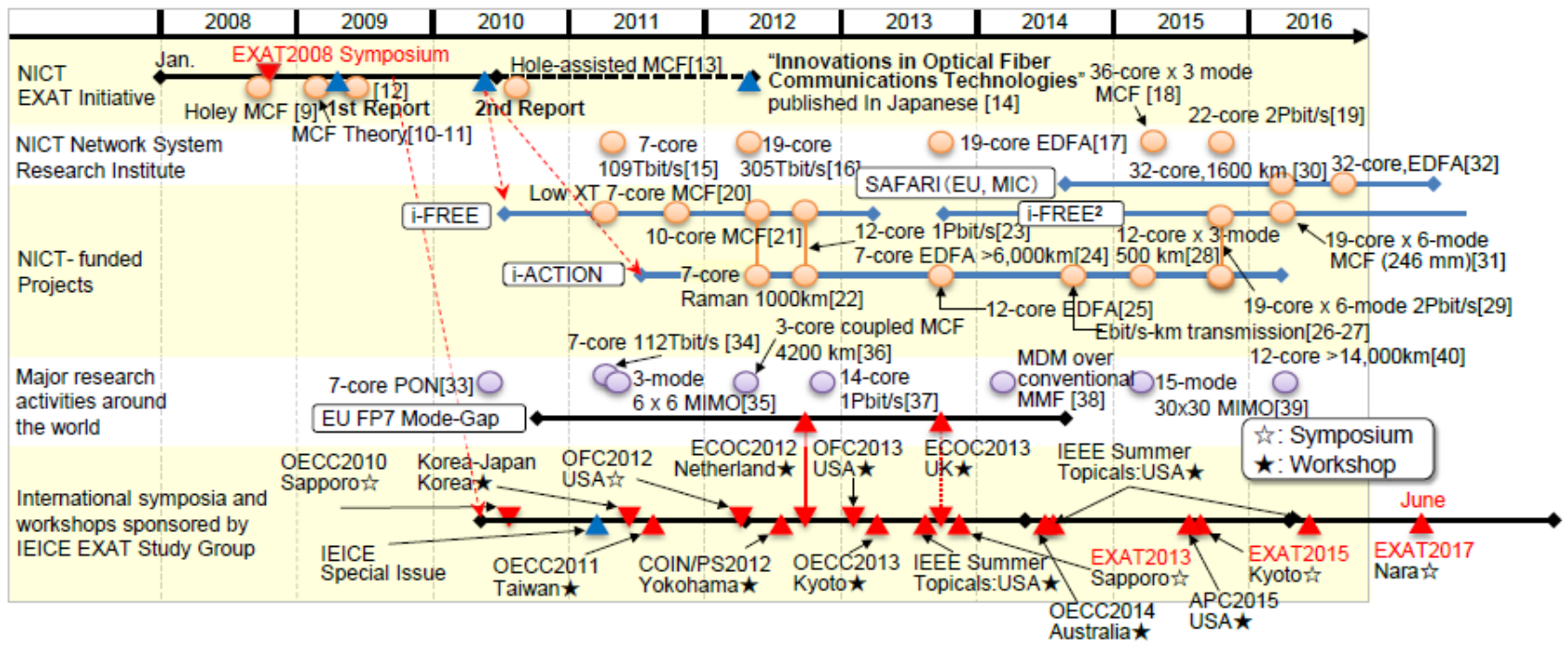

Fig. 3 Development of the EXAT Initiative since 2008. $\begin{array}{ll}\text { Innovative Optical Fiber Technologies } & \begin{array}{l}\text { Innovative Optical Communication } \\ \text { Infrastructure (2011 2015) }\end{array} \\ (2010 \sim 2012) & \end{array}$

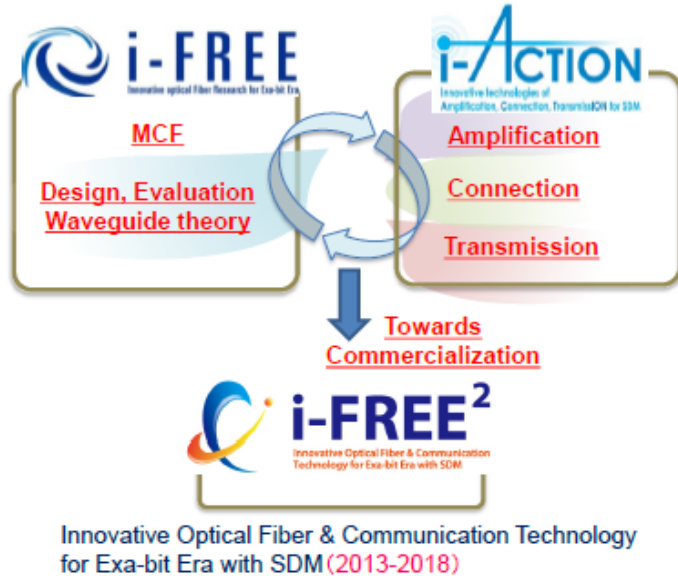

Fig. 4 Major Japanese national projects driven through the EXAT activities.
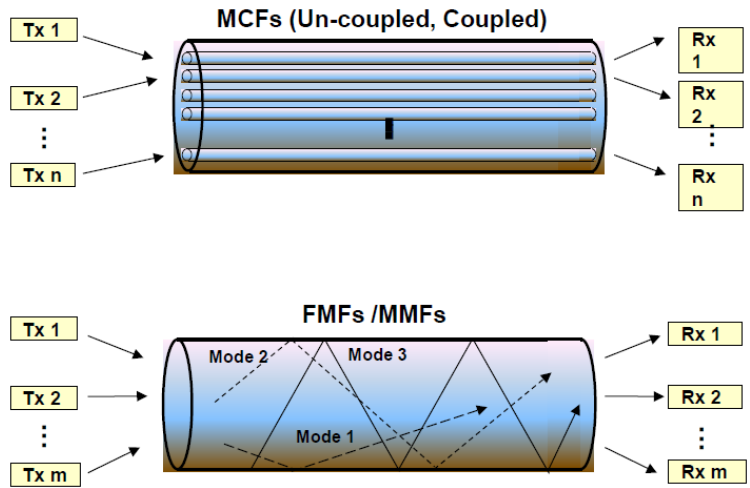

Fig. 5 Schematics of multi-core fibers (MCFs) and few-mode fibers (FMFs) or multi-mode fibers (MMFs).

tion", which we call "3M technologies" [2], [41] as depicted in Fig. 6. It should be noted that EXAT proposed the con-

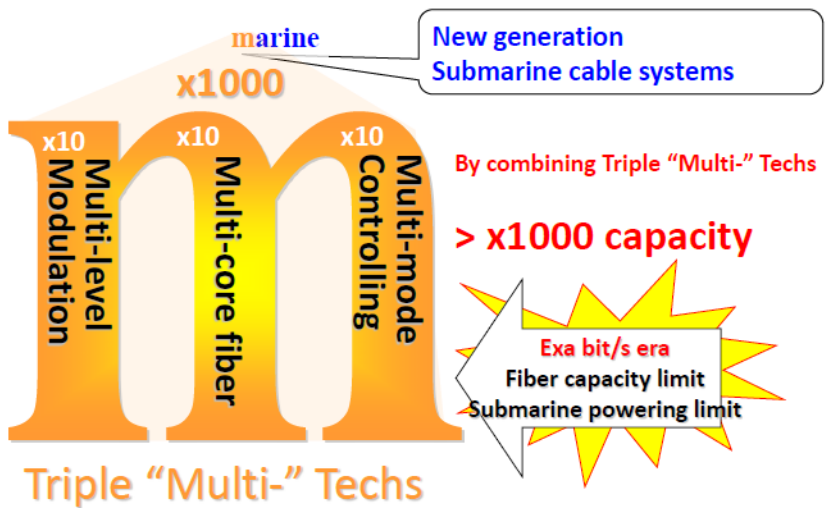

Fig. $63 \mathrm{M}$ technologies.

cept of combining "multi-core" and "multi-mode" for the first time as early as in 2008. Initially, a factor of 10 increase in capacity is considered for each technology, enabling a factor of 1000 increase, but it has been found out that more than a factor of 10 has proven to be possible for "Mutil-core Fiber" and "Multi-mode Control" as more than 30 core fibers [8], [30], [42] and 15 mode [39] transmission have already been demonstrated.

When multiple independent modes in an FMF or MMF are used as an independent channel, the scheme is particularly called MDM while in a broader sense, SDM refers to transmission schemes based on MCFs or FMFs/MMFs. More recently, even few-mode, multi-core fibers (FMMCFs) have been demonstrated as a combination of the two fibers to further increase the transmission capacity [28], [31]. The major new components for SDM are SDM multiplexers (SDM-MUXs) to couple light from different cores or different modes into SDM fibers, SDM fibers, SDM optical amplifiers to amplify SDM signals, SDM demultiplexers (SDM-DEMUXs), optical connectors/splicing as illustrated in Fig. 7. Major important characteristics of the passive components are naturally low insertion loss, low core/mode 


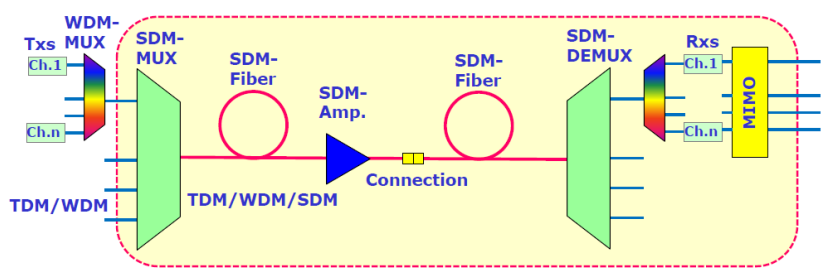

Fig. 7 Basic components for SDM technologies.

dependent loss, low crosstalk among modes/cores and wide bandwidth to support WDM/SDM signals. Optical amplifiers designed for SDM transmission are also a challenge where low core/mode/wavelength dependent, wide bandwidth amplification characteristics with high gain and low noise figures (NFs) are desirable.

\section{Recent Progress in SDM Technologies}

\subsection{SDM Fiber and SDM Amplifier Technologies}

Figure 8 categorizes various SDM fibers [9]-[13], [18], [20], [21], [31], [42]-[49]. So far, FMFs, single-mode (SM)MCFs (uncoupled, coupled) and FM-MCFs have mainly been fabricated and tested in transmission experiments. The main issue with FMFs is how the differential mode delay (DMD) can be reduced to minimize the MIMO complexity whereas that with SM-MCFs is how we can reduce the inter-core crosstalk while increasing the number of cores for higher capacity transmission.

Figure 9 summarizes recently fabricated high-count SM-MCFs. The core layouts can be hexagonal close-packed structure (HCPS), one-ring structure (ORS), dual-ring structure (DRS), and square-lattice structure (SLS). The first one $\mathrm{Pbit} / \mathrm{s}$ experiment was made with a 12 core MCF with ORS [23]. The largest number of cores reported so far is 32 [42] and the fiber has been tested in a $>1600 \mathrm{~km}$ transmission experiment [30]. The 22-core MCF has also been successfully used in $2.15 \mathrm{Pbit} / \mathrm{s}$ transmission [9]. The cladding diameters should be limited to around $250 \mu \mathrm{m}$ or less from the constraints of mechanical reliability comparable to that of the existing telecommunication network where a feasible proof level of $1 \sim 2 \%$ is assumed with a bending radius of $15 \mathrm{~mm}$ [31], [46], [49].

Figure 10 also summarizes recently fabricated FMMCFs for dense-SDM (DSDM) with a spatial multiplicity (channels) of more than 30 where it is defined by a product of number of cores and the number of modes. FM-MCFs with more than 100 spatial channels have already been fabricated and one of them has been used in $2.05 \mathrm{Pbit} / \mathrm{s}$ transmission [29]. A 6-mode, 19-core FM-MCF (far right) has been fabricated with a cladding diameter of less than $250 \mu \mathrm{m}$ and low DMD of $330 \mathrm{ps} / \mathrm{km}$ [31], [49].

SDM amplifiers play an important role in long-haul SDM transmission systems [32], [51]-[54]. Figure 11 summarizes multi-core amplifiers where there are two different pumping schemes, namely, a core-pumping scheme and a cladding pumping scheme. The advantages of the latter are

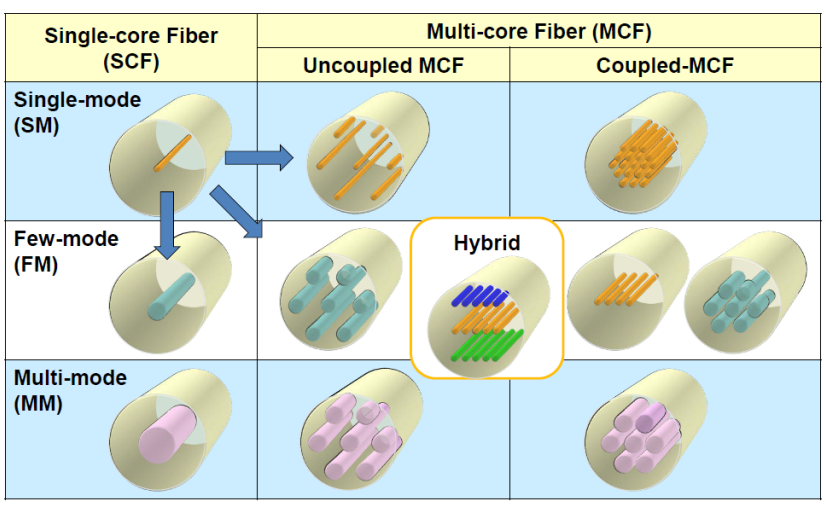

Fig. 8 Categorization of SDM fibers.

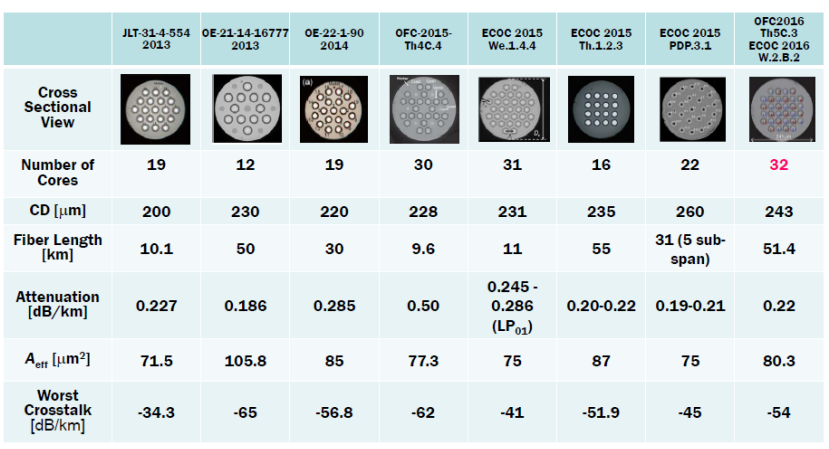

Fig. 9 Recent fabricated high-count SM-MCFs: courtesy of K. Saitoh [45].

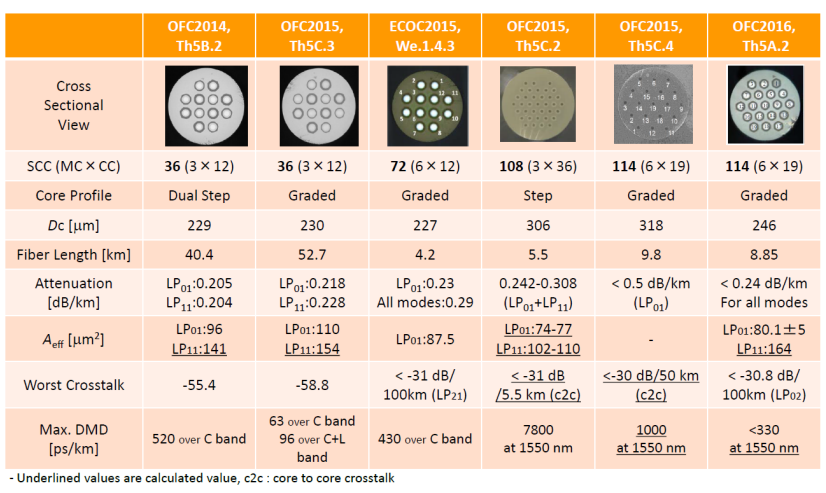

Fig. 10 Recent fabricated FM-MCFs for dense SDM: courtesy of S. Matsuo [46].

that low-cost, high-power multi-mode pump sources can be used and that the number of pump sources can be substantially reduced, providing a much lower cost/bit and energy/bit solution than the core-pumping scheme. Recently, a cladding pumped 32-core EYDFA has been fabricated and used as an inline amplifier in a 32 -core $111.6 \mathrm{~km}$ MCF transmission experiment [32].

\subsection{Recent Transmission Demonstration}

Table 1 summarizes SDM transmission experiments with four different groups of SM-MCFs, coupled-core MCFs, 


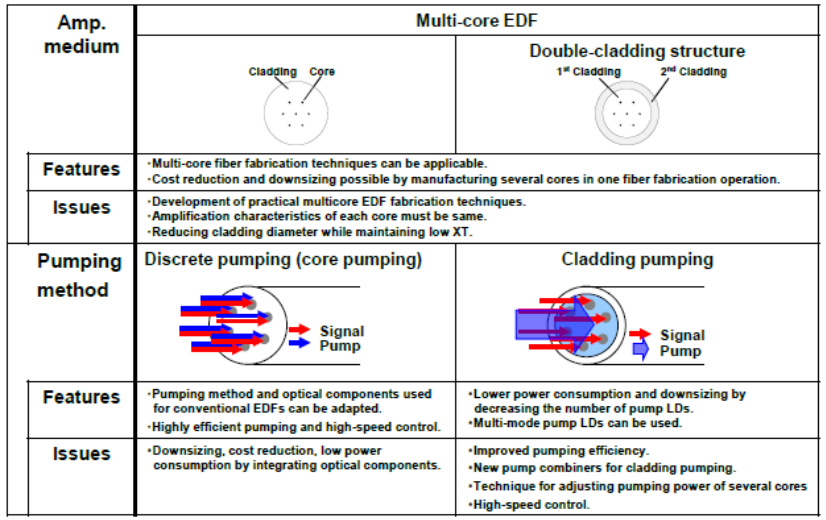

Fig. 11 Multi-core (MC) amplifiers: courtesy of M. Yamada.

Table 1 Transmission experiments using SDM fibers: updated based on [55].

\begin{tabular}{|c|c|c|c|c|c|c|c|c|}
\hline \multicolumn{2}{|c|}{ SDM Fiber } & \multirow{2}{*}{$\begin{array}{l}\text { Amplification } \\
\text { scheme }\end{array}$} & \multirow{2}{*}{$\begin{array}{c}\text { Distance } \\
(\mathrm{km})\end{array}$} & \multirow{2}{*}{$\begin{array}{l}\text { Capacity } \\
(\mathrm{Tb} / \mathrm{s})\end{array}$} & \multirow{2}{*}{$\begin{array}{c}\text { BW } \\
(\mathrm{THz})\end{array}$} & \multicolumn{2}{|c|}{ Efficiencies } & \multirow{2}{*}{$\begin{array}{c}\text { Aggregate } \\
\text { spectral } \\
\text { efficiency } \\
\text { (b/s/Hz) }\end{array}$} \\
\hline Fiber type & $\begin{array}{r}\text { Cladding } \\
\text { DIA }(\mu \mathrm{m})\end{array}$ & & & & & $\underset{\left(1 / \mathrm{mm}^{2}\right)}{\eta_{\text {spatial }}}$ & $\begin{array}{c}\eta_{\text {spectral }} \\
(\mathrm{b} / \mathrm{s} / \mathrm{Hz})\end{array}$ & \\
\hline 7-core & 150 & - & 16.8 & 109 & 9.7 & 396.1 & 1.6 & 11.2 \\
\hline 7-core & 186.5 & - & 76.8 & 112 & 8.0 & 256.2 & 2.0 & 14.0 \\
\hline 7-core & 196 & MC-EDFA & 7326 & 140.7 & 5.0 & 232.0 & 4.0 & 28.0 \\
\hline 7-core & 195 & MCF-ROPA & 204 & 120.7 & 2.25 & 234.4 & 7.6 & 53.6 \\
\hline 7-core & $\mathrm{n} / \mathrm{a}$ & MC-EDFA & 2520 & 51.1 & 5.1 & $\mathrm{n} / \mathrm{a}$ & 1.5 & 10.6 \\
\hline 12-core & 225 & - & 52 & 1014 & 11.1 & 301.8 & 7.6 & 91.4 \\
\hline 12-core & 230 & $\begin{array}{l}\text { MC-EDFA and } \\
\text { Raman }\end{array}$ & 450 & $2 \times 409$ & 10.2 & 288.8 & 6.7 & 80.6 \\
\hline 12 -core & 230 & $\begin{array}{l}\text { MC-EDFA and } \\
\text { Raman }\end{array}$ & 1500 & $2 \times 344$ & 9.4 & 288.8 & 6.1 & 73.6 \\
\hline 12-core & $\mathrm{n} / \mathrm{a}$ & SM-EDFAs & 14530 & 105.1 & 2.7 & - & 3,2 & 38.4 \\
\hline 19-core & 200 & - & 10.1 & 305 & 10.0 & 604.8 & 1.6 & 30.5 \\
\hline 22-core & 260 & - & 31 & 2150 & 10.0 & 414.4 & 9.8 & 215.6 \\
\hline 32-core & 243 & MC-EDFA & 1644.8 & 50.4 & 2.5 & & 6.3 & 201.5 \\
\hline 3 coupled-core & 125 & SM-EDFAs & 4200 & 1.2 & 0.25 & 244.5 & 1.3 & 4.03 \\
\hline 6 coupled-core & 125 & SM-EDFAs & 1705 & 18 & 1.0 & 488.9 & 3.0 & 18.0 \\
\hline 12 -core $\times 3$-mode & 229 & - & 40.4 & 61.97 & 0.25 & 874.1 & 6.88 & 247.9 \\
\hline 12-core $\times 3$-mode & 230 & FM-EDFAs & 527 & 23.58 & 0.25 & 866.5 & 2.62 & 94.3 \\
\hline 7-core $\times 3$-mode & 192 & - & 1 & 200 & 2.5 & 725.3 & 3.8 & 80.0 \\
\hline 36-core $\times 3$-mode & 306 & - & 5.5 & - & - & 1468.6 & - & - \\
\hline 19-core $\times 6$-mode & 318 & - & 9.8 & 30.3 & 0.09 & 1435.4 & 3.03 & 345.0 \\
\hline 19-core $\times 6$-mode & 318 & - & 9.8 & 2050 & 4.5 & 1435.4 & 4.0 & 456.0 \\
\hline 3-mode & 125 & FM-EDFA & 119 & 57.6 & 4.8 & 244.5 & 4.0 & 12.0 \\
\hline 3-mode & 125 & FM-EDFA & $\begin{array}{c}500 \\
1000\end{array}$ & $\begin{array}{c}27.7 \\
3.0\end{array}$ & $\begin{array}{l}3.7 \\
0.4\end{array}$ & 244.5 & 2.5 & 7.6 \\
\hline 3-mode & 125 & Raman & 1050 & 18 & 2.0 & 244.5 & 3.0 & 9.0 \\
\hline 6-mode & 125 & SM-EDFAs & 177 & 24.6 & 0.8 & 488.9 & 5.3 & 32.0 \\
\hline 6 -mode & 125 & SM-EDFAs & 708 & 6.1 & 0.4 & 488.9 & 2.7 & 16.0 \\
\hline 6-mode & 125 & - & 74.17 & 34.6 & 4.3 & 488.9 & 1.3 & 8.1 \\
\hline 6-mode & 125 & FM-EDFA & 179 & 72 & 4.0 & 488.9 & 3.0 & 18.0 \\
\hline 10-mode & 125 & - & $\begin{array}{c}125 \\
87\end{array}$ & $\begin{array}{c}23.2 \\
115.2\end{array}$ & $\begin{array}{l}0.8 \\
4.0\end{array}$ & 814.9 & 2.9 & 29.0 \\
\hline 15 -mode & 125 & - & 22.8 & 17.2 & 0.4 & 1222.3 & 2.9 & 43.6 \\
\hline
\end{tabular}

FM-MCFs, and FMFs/MMFs from the top to the bottom, respectively. The highest capacity is $2.15 \mathrm{Pbit} / \mathrm{s}$ (22-core SM-MCF, $31 \mathrm{~km}$ ) [19] and 2.05 Pbit/s (19 core x 6 mode FM-MCF, 9.8 km) [29] as described earlier while the highest spatial multiplicity is over 100 (108 (36 core x 3 mode), 114 (19 core $\mathrm{x} 6$ mode)). The largest capacity-distance product has already achieved more than one Ebit/s-km [26], [27], and has reached 4.59 Ebit/s-km recently [56]. Figures 12, 13, 14 show capacity per fiber, spatial multiplicity, aggregate SE vs. transmission distance, respectively. It can be seen from the figures that most long-distance demonstrations have been done with SM-MCFs. It should be noted that we set a spatial multiplicity of more than 30 as an initial target which is regarded as the maximum number of cores within a $250 \mu \mathrm{m}$ cladding diameter with the present technologies. We also

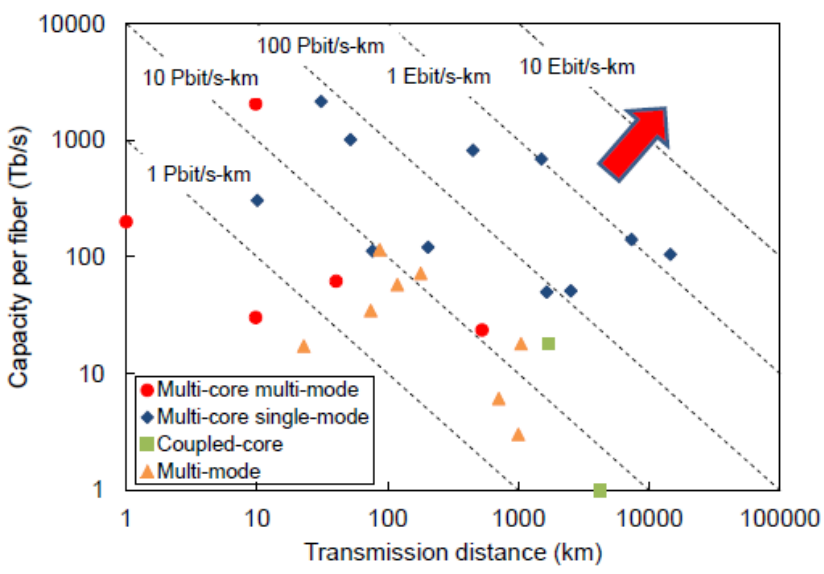

Fig. 12 Capacity vs. transmission distance of recent SDM transmission experiments: updated based on [55].

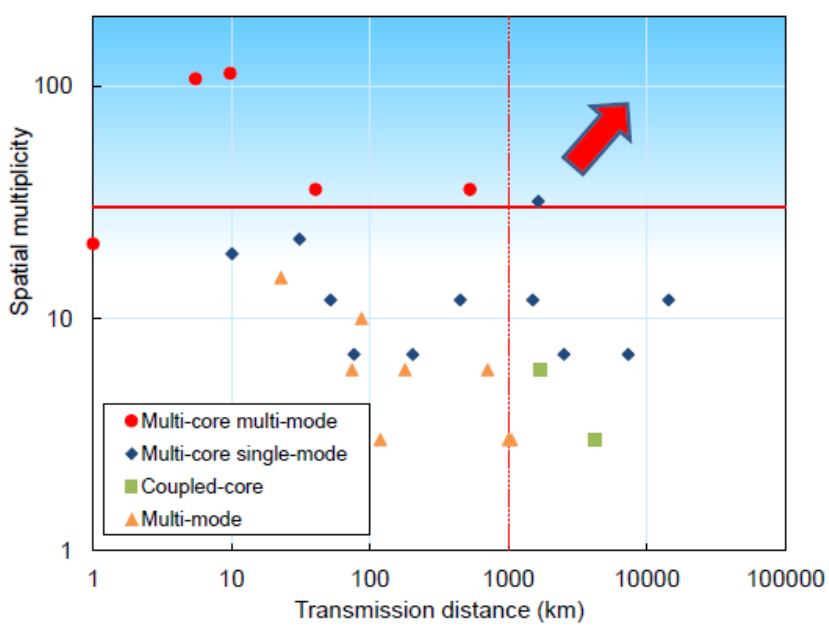

Fig. 13 Spatial multiplicity vs. transmission distance of recent SDM transmission experiments: the red horizontal line corresponds to a spatial multiplicity of 30 for DSDM: updated based on [55].

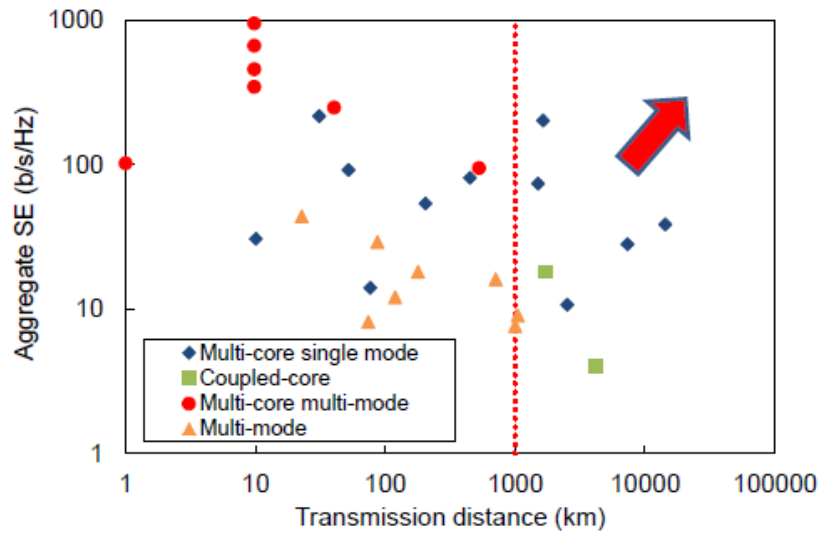

Fig. 14 Aggregate spectral efficiency (SE) vs. transmission distance of recent SDM transmission experiment: updated based on [55].

target a minimum transmission distance of $1000 \mathrm{~km}$ which is required for terrestrial links. 


\section{Future Perspective}

In terms of "Multi-level Modulation" of the $3 \mathrm{M}$ technologies, $64 \mathrm{QAM}$ (6 bit/symbol) is now being developed for commercialization, and more than 1024 QAM (10 bit/symbol) is being studied [57] where the transmission reach is a major research issue for future implementation. In terms of "Mutilcore Fiber" and "Multi-mode Control", 19-core, 6-mode (114 spatial channels) [19], [31], [49], 36-core, 3 mode (108 spatial channels) [29] FM-MCFs have been fabricated and a factor of around 600 increase has already been achieved by the present $3 \mathrm{M}$ technologies. It can be said that by adopting more advanced forward error correction (FEC) algorithms and higher "Multi-level Modulation" formats, a factor of 1000 would be achievable where narrower linewidth laser sources will also be a research issue. The recent progress in ultrafast repeater technology [58] may enable us to employ beyond 1024QAM formats with effectively equivalent transmission distance in the future. The criterion of whether a set of most advanced 3M technology may or may not be introduced depends on the market needs of ultra-wideband network. The continuing global trend of the quick penetration of broadband network services not only in developed countries but also in developing countries convinces us of the deployment of most advanced 3M systems in the long run.

Although the ultimate goal of Exa bit/s capacity per fiber seems quite far away, we can think of roughly four steps towards it. In the first step, we will aim at $10 \mathrm{Pbit} / \mathrm{s}$ capacity using around 30 cores and 6 modes with 180 spatial channels, which will probably be achieved within a few years. In the second step, we will aim at 50-60 Pbit/s using around 50 cores and 15 modes with 700-800 spatial channels, while in the third step, we will aim at $300 \mathrm{Pbit} / \mathrm{s}$ using around 50 cores and 15 modes with $700-800$ spatial channels, while in the third step, we will need to fully utilize the whole $60 \mathrm{THz}$ band (O, E, S, C, L, U) to achieve the capacity. Unfortunately, no specific measures to go up to $1 \mathrm{Ebit} / \mathrm{s}$ in the fourth step are yet known.

Schemes that enable the deployment of SDM technologies in future commercial systems need to be considered. Even though excellent capabilities of SDM technologies have been demonstrated in the research level, their deployment in real systems requires further efforts and the following questions should be answered:

(a) What would be the best application fields?

(b) What scheme would allow smooth migration from existing systems?

(c) How can the cost of the new systems be evaluated?

(d) What will the standardization scheme be?

(e) When will the new system be commercialized?

(f) Who will be the major players?

These questions are closely related to each other. The component cost could be substantially reduced by increasing the market size and therefore, worldwide standardization would be beneficial although detailed discussion of standardization may be time consuming, thereby hindering early deployment. A business exploiting specific transmission routes carrying heavy traffic, such as a super-realistic video service or datacenter-based service might become a frontrunner.

Core network systems consist of many existing optical networks based on traditional SMFs. Therefore, worldwide deployment would require standardization. Future largescale replacement or newly constructed optical networks would present opportunities for the deployment of SDM. Submarine optical cable systems seem to constitute "green field" development, which means that the first stage of the system is not standardized. The space factor is a very important issue in submarine systems because of the limited space in which to locate undersea optical cables and repeaters. SDM essentially offers high space efficiency. The next jump in the transmission capacity of submarine systems may come from SDM when the electric power consumption of the optical amplifier in the repeater nearly may reach the same level as that of current commercial systems.

Candidate application fields of SDM technologies would be submarine systems, access networks/mobile networks in addition to core networks. Short-reach communication systems seem to be suitable application fields for which a rapid increase in traffic can be foreseen. However, as the cost balance will be a key issue in these fields, very low components/construction costs will be needed.

The data-com. field, which includes intra-datacenter signal transmission involving signaling between large numbers of racks/boards, is a promising area for SDM application. Datacenters are expected to require very large capacity signal transmission in combination with simple connections between optical fiber cables, because the space factor is a major issue. Even now, many fiber cables are connected in a complicated manner and SDM offers a solution for this complexity. The integration of the optical components of SDM would also substantially reduce the number of components in a datacenter. The use of SDM fiber transmission over short distances would obviate the need for optical amplifiers. Furthermore, data-com. systems seem to be "green field" implementations, where the preferred network should only be determined by an operator of the particular datacenter. However, data-com. demands real-time communication and low electric power consumption, which requires the MIMO chip in MDM to be carefully designed for actual application.

Thus far, studies of SDM technologies have mainly focused on point-to-point transmission to achieve a very large transmission capacity exceeding $1 \mathrm{Pbit} / \mathrm{s} /$ fiber. However, the networking design and architecture of real systems are important and need necessary consideration. The elastic node architecture of SDM will open the way to additional benefits such as high-contention resolution and much higher throughput by utilizing new dimensions of SDM. Exploration of the potential of the new field calls for the contribution of many ideas from various research areas other than optical communication and for researchers from these areas to become involved in the research field of SDM technologies. 


\section{Acknowledgments}

We would like to thank members of IEICE EXAT study group, those of SAFARI project, Prof. Kunimasa Saitoh of Hokkaido University, Dr. Shoichiro Matsuo of Fujikura Ltd., Dr. Takayuki Mizuno of NTT Network Innovation Labs., Prof. Makoto Yamada of Osaka Prefecture University, Japan and Dr. Klaus Werner of the National Institute of Information and Communications Technology (NICT), Japan for fruitful discussion. Part of this work is supported by the EUJapan coordinated R\&D project on "Scalable And Flexible optical Architecture for Reconfigurable Infrastructure (SAFARI)" commissioned by the Ministry of Internal Affairs and Communications (MIC) of Japan and EC Horizon 2020 and Innovationsfonden e-space (0603-00514B).

\section{References}

[1] E.B. Desurvire, "Capacity demand and technology challenges for lightwave systems in the next two decades," J. Lightwave Technol., vol.24, no.12, pp.4697-4710, 2006.

[2] T. Morioka, "New generation optical infrastructure technologies: "EXAT initiative: Towards 2020 and beyond," OECC 2009, FT4, 2009.

[3] R.-J. Essiambre, G. Kramer, P.J. Winzer, G.J. Foschini, and B. Goebel, "Capacity limits of optical fiber networks," J. Lightwave Technol., vol.28, no.4, pp.662-701, 2010.

[4] P.J. Winzer, "Energy-efficient optical transport capacity scaling through spatial multiplexing," IEEE Photon. Technol. Lett., vol.23, no.13, pp.851-853, 2011.

[5] T. Morioka, Y. Awaji, R. Ryf, P. Winzer, D. Richardson, and F. Poletti, "Enhancing optical communications with brand new fibers," IEEE Commun. Mag., vol.50, no.2, pp.s31-s42, 2012.

[6] D.J. Richardson, J.M. Fini, and L.E Nelson, "Space-division multiplexing in optical fibres," Nature Photonics, vol.7, no.5, pp.354-362, 2013

[7] S. Inao, T. Sato, S. Sentsui, T. Kuroha, and Y. Nishimura, "Multicore optical fiber," OFC1979, WB1, 1979.

[8] S. Berdague and P. Facq, "Mode division multiplexing in optical fibers," Appl. Opt., vol.21, no.11, pp.1950-1955, 1982.

[9] K. Imamura, K. Mukasa, R. Sugizaki, Y. Mimura, and T. Yagi, "Multi-core holey fibers for ultra large capacity wide-band transmission," ECOC 2008, P.1.17, 2008

[10] Y. Kokubun and M. Koshiba, "Novel multi-core fibers for mode division multiplexing: Proposal and design principle," IEICE Electron. Express, vol.6, no.8, pp.522-528, 2009.

[11] M. Koshiba, K. Saitoh, and Y. Kokubun, "Heterogeneous multi-core fibers: Proposal and design principle," IEICE Electron. Express, vol.6, no.2, pp.98-103, 2009.

[12] K. Imamura, K. Mukasa, Y. Mimura, and T. Yagi, "Multi-core holey fibers for the long-distance $(>100 \mathrm{~km})$ ultra large capacity transmission," OFC 2009, OTuC3, 2009.

[13] K. Saitoh, T. Matsui, T. Sakamoto, M. Koshiba, and S. Tomita, "Multi-core hole-assisted fibers for high core density space division multiplexing," OECC 2010 Technical Digest, pp.164-165, 2010.

[14] M. Nakazawa, M. Suzuki, and T. Morioka, Innovations in Optical Fiber Communications Technologies, Optronics Corporation, (ISBN: 978-4-902312-50-8), 2012

[15] J. Sakaguchi, Y. Awaji, N. Wada, A. Kanno, T. Kawanishi, T. Hayashi, T. Taru, T. Kobayashi, and M. Watanabe, "109-Tb/s $(7 \times 97 \times 172-\mathrm{Gb} / \mathrm{s}$ $\mathrm{SDM} / \mathrm{WDM} / \mathrm{PDM}$ ) QPSK transmission through 16.8-km homogeneous multi-core fiber," OFC/NFOEC 2011, PDPB6, 2011.

[16] J. Sakaguchi, B.J. Puttnam, W. Klaus, Y. Awaji, N. Wada, A. Kanno,
T. Kawanishi, K. Imamura, H. Inaba, K. Mukasa, R. Sugizaki, T. Kobayashi, and M. Watanabe, "19-core fiber transmission of 19x100x172-Gb/s SDM-WDM-PDM-QPSK signals at $305 \mathrm{~Tb} / \mathrm{s}$,' OFC/NFOEC 2012, PDP5C.1, 2012.

[17] J. Sakaguchi, W. Klaus, B.J. Puttnam, J.-M.D. Mendinueta, Y. Awaji, N. Wada, Y. Tsuchida, K. Maeda, M. Tadakuma, K. Imamura, R. Sugizaki, T. Kobayashi, Y. Tottori, M. Watanabe, and R.V. Jensen, "19-core MCF transmission system using EDFA with shared core pumping coupled in free-space optics," ECOC 2013, Th.1.C.6, 2013.

[18] J. Sakaguchi, W. Klaus, J.M. Delgado Mendinueta, B.J. Puttnam, R.S. Luis, Y. Awaji, N. Wada, T. Hayashi, T. Nakanishi, T. Watanabe, Y. Kokubun, T. Takahata, and T. Kobayashi, "Realizing a 36-core, 3-mode Fiber with 108 Spatial Channels," OFC 2015, Th5C.2, 2015.

[19] B.J. Puttnam, R.S. Luís, W. Klaus, J. Sakaguchi, J.-M. Delgado Mendinueta, Y. Awaji, N. Wada, Y. Tamura, T. Hayashi, M. Hirano and $\mathrm{J}$. Marciante, " $2.15 \mathrm{~Pb} / \mathrm{s}$ transmission using a 22 core homogeneous single-mode multi-core fiber and wideband optical comb," European Conference and Exhibition on Optical Communication, 2015, p.PDP.3.1, 2015.

[20] T. Hayashi, T. Taru, O. Shimakawa, T. Sasaki, and E. Sasaoka, "Ultralow-crosstalk multi-core fiber feasible to ultra-long-haul transmission," OFC 2011, PDPC2, 2011.

[21] S. Matsuo, K. Takenaga, Y. Arakawa, Y. Sasaki, S. Taniagwa, K. Saitoh, and M. Koshiba, "Large-effective-area ten-core fiber with cladding diameter of about $200 \mu \mathrm{m}$," Opt. Lett., vol.36, no.23, pp.4626-4628, 2011

[22] H. Takara, H. Ono, Y. Abe, H. Masuda, K. Takenaga, S. Matsuo, H. Kubota, K. Shibahara, T. Kobayashi, and Y. Miyamoto, "1000$\mathrm{km}$ 7-core fiber transmission of $10 \times$ 96-Gb/s PDM-16QAM using Raman amplification with 6.5W per fiber," Opt. Exp., vol.20, no.9, pp.10100-10105, 2012.

[23] H. Takara, A. Sano, T. Kobayashi, H. Kubota, H. Kawakami, A Matsuura, Y. Miyamoto, Y. Abe, H. Ono, K. Shikama, Y. Goto, K. Tsujikawa, Y. Sasaki, I. Ishida, K. Takenaga, S. Matsuo, K. Saitoh, M. Koshiba, and T. Morioka, "1.01-Pb/s (12 SDM/222 WDM/456 Gb/s) crosstalk-managed transmission with $91.4-\mathrm{b} / \mathrm{s} / \mathrm{Hz}$ aggregate spectral efficiency," ECOC 2012, Th.3.C.1, 2012.

[24] H. Takahashi, T. Tsuritani, E. Le Taillandier de Gabory, T. Ito, W. Peng, K. Igarashi, K. Takeshima, Y. Kawaguchi, I. Morita, Y. Tsuchida, Y. Mimura, K. Maeda, T. Saito, K. Watanabe, K. Imamura, R. Sugizaki, and M. Suzuki, "First demonstration of MC-EDFArepeatered SDM transmission of $40 \times 128-G b i t / s$ PDM-QPSK signals per core over 6,160-km 7-core MCF," ECOC 2012, Th.3.C.3, 2012

[25] H. Ono, K. Takenaga, K. Ichii, S. Matsuo, T. Takahashi, H. Masuda, and M. Yamada, "12-core double-clad Er/Yb-doped fiber amplifier employing free-space coupling pump/signal combiner module," ECOC. 2013, We.4.A.4, 2013

[26] K. Igarashi, T. Tsuritani, I. Morita, Y. Tsuchida, K. Maeda, M. Tadakuma, T. Saito, K. Watanabe, R. Sugizaki, and M. Suzuki, "1.03-Exabit/s-km super-Nyquist-WDM transmission over 7,326-km seven-core Fiber," ECOC 2013, Paper PDP3.E.3, 2013.

[27] T. Kobayashi, H. Takara, A. Sano, T. Mizuno, H. Kawakami, Y Miyamoto, K. Hiraga, Y. Abe, H. Ono, M. Wada, Y. Sasaki, I. Ishida, K. Takenaga, S. Matsuo, K. Saitoh, M. Yamada, H. Masuda, and T. Morioka, " 2 x $344 \mathrm{~Tb} / \mathrm{s}$ propagation-direction interleaved transmission over 1500-km MCF enhanced by multicarrier full electric-field digital back-propagation," European Conference and Exhibition on Optical Communication, 2013, p.PD3.E.4, 2013

[28] K. Shibahara, T. Mizuno, H. Takara, A. Sano, H. Kawakami, D. Lee, Y. Miyamoto, H. Ono, M. Oguma, Y. Abe, T. Kobayashi, T. Matsui, R. Fukumoto, Y. Amma, T. Hosokawa, S. Matsuo, K. Saitoh, H. Nasu, and T. Morioka, "Dense SDM (12-core $\times 3$-mode) transmission over $527 \mathrm{~km}$ with 33.2-ns mode-dispersion employing lowcomplexity parallel MIMO frequency-domain equalization," OFC 2015, Th5C.3, 2015.

[29] D. Soma, K. Igarashi, Y. Wakayama, K. Takeshima, Y. Kawaguchi, 
N. Yoshikane, T. Tsuritani, I. Morita, and M. Suzuki, "2.05 Petabit/s super-nyquist-WDM SDM transmission using 9.8-km 6-mode 19-core fiber in full C band," ECOC 2015, PDP3.2, 2015.

[30] T. Mizuno, K. Shibahara, F. Ye, Y. Sasaki, Y. Amma, K. Takenaga, Y. Jung, K. Pulverer, H. Ono, Y. Abe, M. Yamada, K. Saitoh, S. Matsuo, K. Aikawa, M. Bohn, D.J. Richardson, Y. Miyamoto, and T. Morioka, "Long-haul dense space division multiplexed transmission over low-crosstalk heterogeneous 32-core transmission line using partial recirculating loop system," J. Lightwave Technol., Special issue on the Optical Fiber Communication Conference (OFC) 2016, vol.35, no.3, pp.488-498, 2016.

[31] T. Sakamoto, T. Matsui, K. Saitoh, S. Saitoh, K. Takenaga, T. Mizuno, y. abe, K. Shibahara, Y. Tobita, S. Matsuo, K. Aikawa, S. Aozasa, K. Nakajima, and Y. Miyamoto, "Low-loss and Low-DMD few-mode multi-core fiber with highest core multiplicity factor," OFC 2016, Th5A.2, 2016.

[32] S. Jain, T. Mizuno, Y. Jung, J. Hayes, G. Bai, H. Ono, K. Shibahara, Q. Kang, M. Petrovich, A. Sano, A. Isoda, Y. Miyamoto, Y. Sasaki, Y. Amma, K. Takenaga, K. Aikawa, C. Castro, K. Pulverer, M. Nooruzzaman, T. Morioka, S. Alam, and D.J. Richardson, "32-core inline multicore fiber amplifier for dense space division multiplexed transmission systems," ECOC 2016, Th.3.A.1, 2016.

[33] B. Zhu, T.F. Taunay, M.F. Yan, J.M. Fini, M. Fishteyn, E.M. Monberg, and F.V. Dimarcello, "Seven-core multicore fiber transmissions for passive optical network," Opt. Express, vol.18, no.11, pp.11117-11122, 2010.

[34] B. Zhu, T.F. Taunay, M. Fishteyn, X. Liu, S. Chandrasekhar, M.F. Yan, J.M. Fini, E.M. Monberg, and F.V. Dimarcello, "112-Tb/s spacedivision multiplexed DWDM transmission with $14-\mathrm{b} / \mathrm{s} / \mathrm{Hz}$ aggregate spectral efficiency over a 76.8-km seven-core fiber," Opt. Exp., vol.19, no.17, pp.16665-16671, 2011.

[35] S. Randel, R. Ryf, A.H. Gnauck, M.A. Mestre, C. Schmidt, R.-J. Essiambre, P.J. Winzer, R. Delbue, P. Pupalaikis, A. Sureka, Y. Sun, X. Jiang, and R. Lingle, "Mode-multiplexed 6×20-GBd QPSK transmission over 1200-km DGD-compensated few-mode fiber," OFC 2012, PDP5C.5, 2012.

[36] R. Ryf, R.-J. Essiambre, A.H. Gnauck, S. Randel, M.A. Mestre, C. Schmidt, P.J. Winzer, R. Delbue, P. Pupalaikis, A. Sureka, T. Hayashi, T. Taru, and T. Sasaki, "Space-division multiplexed transmission over $4200 \mathrm{~km}$ 3-core microstructured fiber," OFC/NFOEC 2012, PDP5C.2, 2012.

[37] D. Qian, E. Ip, M.-F. Huang, M.-J. Li, A. Dogariu, S. Zhang, Y. Shao, Y.-K. Huang, Y. Zhang, X. Cheng, Y. Tian, P.N. Ji, A. Collier, Y. Geng, J. Liñares, C. Montero, V. Moreno, X. Prieto, and T. Wang, "1.05 Pb/s transmission with $109 \mathrm{~b} / \mathrm{s} / \mathrm{Hz}$ spectral efficiency using hybrid single- and ffew-mode cores," FiO 2012, FW6C.3, 2012.

[38] R. Ryf, N.K. Fontaine, H. Chen, B. Guan, S. Randel, N. Sauer, S. Yoo, A. Koonen, R. Delbue, P. Pupalaikis, A. Sureka, R. Shubochkin, Y. Sun, and R. Lingle., "23 Tbit/s transmission over 17-km conventional 50- $\mu$ m graded-index multimode fiber," OFC.2014.Th5B.1, 2014.

[39] N.K. Fontaine, R. Ryf, H. Chen, A.V. Benitez, B. Guan, R. Scott, B. Ercan, S.J.B. Yoo, L.E. Grüner-Nielsen, Y. Sun, R. Lingle, E. Antonio-Lopez, and R. Amezcua-Correa, "30×30 MIMO transmission over 15 spatial modes,” OFC 2015, Th5C.1, 2015.

[40] A. Turukhin, O.V. Sinkin, H.G. Batshon, H. Zhang, Y. Sun, M. Mazurczyk, C.R. Davidson, J.-X. Cai, M.A. Bolshtyansky, D.G. Foursa, and A. Pilipetskii, " $105.1 \mathrm{~Tb} / \mathrm{s}$ power-efficient transmission over 14,350 km using a 12-core fiber,” OFC 2016, Th4C.1, 2016.

[41] M. Nakazawa, "Extremely advanced transmission with 3M technologies (multi-level modulation, multi-core \& multi-mode)," OFC/NFOEC 2012, OTu1D.1 (2012). http://ieeexplore.ieee.org/ document/6192018/

[42] Y. Sasaki, R. Fukumoto, K. Takenaga, K. Aikawa, K. Saitoh, T. Morioka, and Y. Miyamoto, "Crosstalk-managed heterogeneous single-mode 32-core fibre," ECOC 2016, W.2.B.2, 2016.

[43] K. Takenaga, Y. Arakawa, S. Tanigawa, N. Guan, S. Matsuo, K. Saitoh, and M. Koshiba, "Reduction of crosstalk by trench-assisted multi-core fiber," OFC/NFOEC 2011, OWJ4, 2011.

[44] T. Hayashi, T. Taru, O. Shimakawa, T. Sasaki, and E. Sasaoka, "Design and fabrication of ultra-low crosstalk and low loss multicore fiber," Opt. Express, vol.19, no.17, pp.16576-16592, 2011.

[45] K. Saito, "High core count single-mode multicore fiber for dense space division multiplexing," IEEE Photon. Soc. Summer Topical Meeting (SUM) 2016, TuE4.1, Newport Beach, CA, USA, 2016.

[46] S. Matsuo, K. Takenaga, K. Saitoh, K. Nakajima, Y. Miyamoto, and T. Morioka, "High-spatial-multiplicity multi-core fibres for future dense space-division-multiplexing system," ECOC 2015, Th.1.2.1, 2015.

[47] T. Hayashi, Y. Tamura, T. Hasegawa, and T. Taru, " $125-\mu$ m-cladding coupled multi-core fiber with ultra-low loss of $0.158 \mathrm{~dB} / \mathrm{km}$ and record-low spatial mode dispersion of $6.1 \mathrm{ps} / \mathrm{km}^{1 / 2}$," OFC 2016, Th5A.1, 2016.

[48] L. Grüner-Nielsen, Y. Sun, J.W. Nicholson, D. Jakobsen, R. Lingle, Jr, and B. Pálsdóttir, "Few mode transmission fiber with low DGD, low mode coupling and low loss," OFC/NFOEC 2012, PDP5A.1, 2012.

[49] T. Sakamoto, T. Matsui, K. Saitoh, S. Saitoh, K. Takenaga, T. Mizuno, Y. Abe, K. Shibahara, Y. Tobita, S. Matsuo, K. Aikawa, S. Aozasa, K. Nakajima, and Y. Miyamoto, "Low-loss and lowDMD 6-mode 19-core fiber with cladding diameter of less than $250 \mu$ m," IEEE J. Lightw. Technol., vol.35, no.3, pp.443-449, DOI: 10.1109/JLT.2016.2610479, 2016.

[50] D. Souma, Y. Wakayama, K. Takeshima, Y. Kawaguchi, N. Yoshikane, T. Tsuritani, I. Morita, and M. Suzuki, "Ultra-dense spatial-division-multiplexed optical fiber transmission over 6-mode 19-core fibers," Opt. Express, vol.24, no.10, pp.10213-10231, 2016.

[51] K.S. Abedin, T.F. Taunay, M. Fishteyn, D.J. DiGiovanni, V.R. Supradeepa, J.M. Fini, M.F. Yan, B. Zhu, E.M. Monberg, and F.V. Dimarcello, "Cladding-pumped erbium-doped multicore fiber amplifier," Opt. Express, vol.20, no.18, pp.20191-20200, 2012.

[52] Y. Jung, S. Alam, Z. Li, A. Dhar, D. Giles, I. Giles, J. Sahu, L. Gruner-Nielsen, F. Poletti, and D.J. Richardson, "First demonstration of multimode amplifier for spatial division multiplexed transmission systems," ECOC 2011, Th.13.K.4, 2011.

[53] Y. Mimura, Y. Tsuchida, K. Maeda, R. Miyabe, K. Aiso, H. Matsuura, and R. Sugizaki, "Batch multicore amplification with claddingpumped multicore EDF," 38th European Conference on Optical Communication (ECOC2012), Tu.4.F.1, 2012.

[54] H. Ono, K. Takenaga, K. Ichii, and M. Yamada, "Amplification technology for multi-core fiber transmission," SUM 2014 IEEE Photonics Society Summer Topical Meeting on Space Division Multiplexing for Optical Systems and Networks, ME2.1, 2014.

[55] T. Mizuno, H. Takara, K. Shibahara, A. Sano, and Y. Miyamoto, "Dense space division multiplexed transmission over multicore and multimode fiber for long-haul transport systems," J. Lightwave Technol., vol.34, no.6, pp.1484-1493, 2016.

[56] A. Turukhin, H.G. Batshon, M. Mazurczyk, Y. Sun, C.R. Davidson, J.-X. Chai, O.V. Sinkin, W. Patterson, G. Wolter, M.A. Bolshtyansky, D.G. Foursa, and A. Pilipetskii, "Demonstration of $0.52 \mathrm{~Pb} / \mathrm{s}$ potential transmission capacity over $8,830 \mathrm{~km}$ using multicore fiber," ECOC 2016, Tu.1.D.3, 2016.

[57] S. Beppu, K. Kasai, M. Yoshida, and M. Nakazawa, "2048 QAM (66 Gbit/s) single-carrier coherent optical transmission over $150 \mathrm{~km}$ with a potential SE of $15.3 \mathrm{bit} / \mathrm{s} / \mathrm{Hz}$," Opt. Express, vol.23, no.4, pp.4960-4969, Feb. 2015.

[58] H. Furukawa, J.M.D. Mendinueta, T. Segawa, R. Takahashi, S. Shinada, and N. Wada, "Cascadability performance of a high-speed electro-absorption optical switch for DP-16QAM and DP-QPSK optical signals," ECOC 2016 Th.2.P2.SC, pp.1139-1141, 2016. 


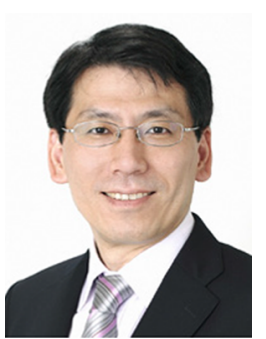

Toshio Morioka received the B.S., M.S. and Ph.D. degrees in Physics and Applied Physics from Waseda University in 1982, 1985 and 1995, respectively, and the M.S. degree from the University of Arizona in 1984. In 1985, he joined NTT Research Labs. in Yokosuka, Japan and is now with Technical University of Denmark. He is a fellow of IEICE and OSA (Optical Society of America). He has been with Technical University of Denmark since 2011.

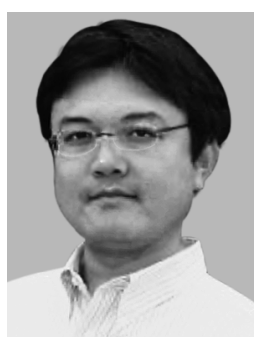

Yoshinari Awaji received the B.E. in electronic physics school in 1991, M.E., and Dr. Eng. degrees in department of information physics in 1993, and 1996, respectively of Tokyo Institute of Technology, Tokyo, Japan. In 1996 he joined the Communications Research Laboratory (CRL: currently NICT). He was engaged in information security strategies at the Cabinet Secretariat from 2004 to 2006 . He has been mainly researching optical signal processing, optical amplifiers, optical packet switching, spacedivision multiplexing and resilient optical network technologies for disaster recovery. He received the Ichimura Academic Award in 2012, Advanced Technology Award (Fuji-Sankei business eye) in 2016. He is a member of IEEE/Photonics Society and IEICE.

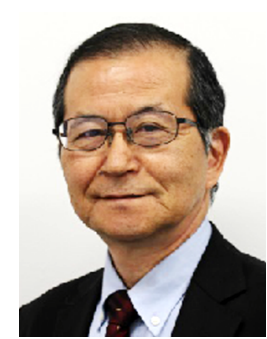

Yuichi Matsushima received the B.E., M.E. and $\mathrm{Ph} . \mathrm{D}$. degrees in electrical engineering from Waseda University in1972, 1974 and 1978, respectively. In 1978, he joined KDD R\&D Laboratories in Tokyo. From 2003 to 2010, he has been with National Institute of Information and Communications Technology (NICT) as a vice president. Since 2010, he has worked as a Professor of Waseda University. He is a fellow of IEICE, IEEE and JSAP (Japan Society of Applied Physics).

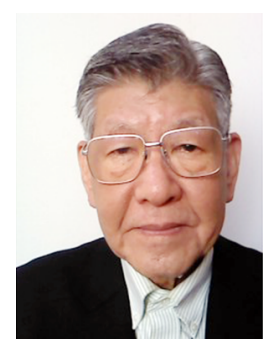

Takeshi Kamiya received B.E., M.E. and Ph.D. degrees in Applied Physics from The University of Tokyo in 1963, 1965 and 1970, respectively. From 1965 till 2000 he served for The University of Tokyo at Departments of Applied Physics and Electronic Engineering as Research Associate, Associate Professor and Professor. In 2000 he was entitled Professor emeritus. From 2000 till 2006 he served for National Institution of University Evaluation and Academic Degrees as Professor and Dean. From 2006 till 2012 he served for National Institute of Communications and Information Technology as Program Director and Advisor on part time basis. He has contributed to high speed semiconductor optoelectronics, optical communication and engineering education. 